\title{
The Relationship Between Afterlife Beliefs and Mental Wellbeing Among Jordanian Muslim Youth
}

\author{
Riyad Salim Al-Issa*, Steven Eric Krauss ${ }^{\dagger}$, Samsilah Roslan ${ }^{\ddagger}$ \\ and Haslinda Abdullah
}

\begin{abstract}
Despite the centrality of beliefs in afterlife reward and punishment in the religious life of Muslims, few empirical studies have sought to understand how such beliefs affect the psychological state and social behavior of Muslims. Past related studies have concluded that these beliefs are unhealthy because they are positively associated with general anxiety and death anxiety. This finding contradicts a central notion in Islamic theology, which states that avoiding afterlife punishment and obtaining afterlife reward is the primary motive for Muslim religiosity. The current study attempts to deepen our understanding of how Islamic afterlife reward and punishment beliefs affect the psychological state of Muslims. The study suggests that the influence of Islamic afterlife beliefs on wellbeing can be better understood from the perspective of meaning management theory as well as through the eudaimonistic tradition. This study has two goals: To develop the Islamic Afterlife Reward and Punishment Beliefs (IARPB) scale and to examine the relationship between IARPB and Muslim religiosity, death anxiety, death acceptance, and integrity. Data were collected from Jordanian university students $(\mathrm{N}=605)$. Exploratory and confirmatory analyses support the construct validity of the IARPB Scale. IARPB positively predicted Muslim religiosity, death anxiety, death acceptance, and integrity. Results of ad hoc analysis indicated that IARPB suppresses death anxiety and amplifies death acceptance by increasing Muslim religiosity. In general, the results indicate a positive relationship between IARPB and the psychological state of Muslims. The limitations of the study and suggestions for future research are discussed.
\end{abstract}

\section{Keywords}

Islam $\bullet$ afterlife beliefs $\bullet$ death anxiety $\bullet$ death acceptance $\bullet$ integrity

\section{Introduction}

Afterlife is a major theme in the Qur'an, the central religious text of Islam (Smith \& Haddad, 2002). One quarter of the verses in the Qur'an relate to the afterlife (Dastmalchian, 2017). The

\footnotetext{
*University Putra Malaysia, alissariyad@gmail.com

†University Putra Malaysia, lateef@upm.edu.my

‡University Putra Malaysia, samsilah@upm.edu.my

【University Putra Malaysia, lynn@upm.edu.my
}

Correspondence concerning this article should be addressed to Steven Krauss, Institute for Social Science Studies, University Putra Malaysia, Serdang, Selangor, 43400, Malaysia.

doi: $10.3998 / \mathrm{jmmh} .125$

Conflicts of interest:

The authors have no conflicts of interest to disclose. 
Qur'an's references to the afterlife describe precise details about the rewards of Heaven and the punishments of Hell (Lange, 2016; Murata \& Chittick, 1994). Due to the importance that the Qur'an gives to the afterlife, the punishment of Hell and the reward of Heaven are an essential part of Islamic religious discourse (Lange, 2008). Muslims typically receive this discourse from their early childhood education, both formal and informal (McCleary, 2007). Belief in resurrection and Divine judgment is a cornerstone of the Islamic faith (Shafer, 2012).

Practicing Muslims recite the same Qur'anic chapter, Surat al-Fatihah (The Opening), in their prayers at least 17 times throughout every day. Al-Fatihah consists of seven verses whose main theme is the afterlife and Day of Judgment and the fate of people on that day. Muslims are among the most adherent believers in the afterlife among the world's major religious groups (Barro \& McCleary, 2003). Stuart (2014, p. 31) reported on the importance that young Muslims attach to afterlife beliefs. One study participant commented: "We are taught that whatever you do, you get back. If you do bad things then you are punished, if you do good then you will be rewarded. Sometimes these rewards and punishments come straight to you, and other times Heaven and Hell are rewards and punishments, and that is afterlife. Right now this belief reminds me all the time who I need to be."

Despite the vital role played by the beliefs of the hereafter in Islam and in the lives of Muslims, there are few empirical studies on the impact of Islamic afterlife beliefs on the mental health of Muslims (Abu-Raiya, 2013). For example, a search for the term "afterlife" in the Journal of Muslim Mental Health produced only five papers, none of which consider afterlife beliefs as an independent or dependent variable.

\section{Islamic Afterlife Beliefs and Mental Health}

The only two known studies that examined the relationship between afterlife beliefs among Muslims in relation to mental health revealed a negative relationship (Haque et al. 2016). Afterlife beliefs were positively associated with anxiety and depression (Ghorbani, Watson, \& Shahmohamadi, 2008), obsessive-compulsive disorder, psychoticism, interpersonal sensitivity, and somatization (Ghorbani, Watson, Ghramaleki, Morris, \& Hood, 2002). These results led the researchers to conclude that "beliefs about Heaven and Hell reflect a wholly unhealthy and defensive religiosity that is incompatible with sincere Muslim beliefs" (Ghorbani et al., 2008, p. 33). However, their conclusion seems inconsistent with their results in the same and other studies. The Afterlife Motivation Scale used in the study showed a positive relationship with intrinsic religiosity and nearness to God (Ghorbani et al., 2008). Another study (Ghorbani, Watson, Geranmayepour, \& Chen, 2014) based on a sample from the same population found that afterlife motivation correlated positively with the Muslim Experiential Religiousness Scale (Islamic spirituality), which contains items that reflect sincere Muslim beliefs such as: "Intimate closeness to God is at the core of my efforts to be religious", "What has given me peace in all of my life difficulties is being in submission to God's will", and "Sometimes, submission to God simultaneously creates within me a fear and a love of God." The Afterlife Motivation Scale also positively correlated with the Attitude Toward Islam Scale and the Intellect and Faith-Oriented Reflection Scale (Muslim quest for meaning; Ghorbani, Watson, Geranmayepour, \& Chen, 2014).

The researchers concluded by stating that one cannot assume that the Afterlife Motivation Scale exhaustively captured all the meanings that Heaven and Hell can have for Muslims, and that it is possible that other afterlife beliefs could be associated with psychosocial benefits. The authors urged further research to explore these possibilities (Ghorbani et al., 2008). Building on this work, in the subsequent sections of this paper we present an alternative explanation for the connection between Islamic afterlife reward and punishment beliefs (IARPB) and mental health. 


\section{IARPB and Death: Anxiety and Acceptance}

The relationship between religion and death anxiety remains unclear. A recent systematic review and meta-analysis of 35 afterlife belief effect sizes provides evidence of a small but significant negative association between death anxiety and afterlife beliefs $(r=-0.06$; Jong et al., 2017). While a meta-analysis of 30 intrinsic religiosity effect sizes points to a small-to-medium negative significant association between death anxiety and intrinsic religiosity $(r=-0.21$; Jong et al., 2017). These findings are mainly based on Western Christian samples (Ellis \& Wahab, 2013; Flannelly, 2017b; Jong et al., 2017). The picture is quite different for Muslim populations, however. Studies have found that Muslims show higher levels of death anxiety than other religions (Abdel-Khalek, Lester, Maltby, \& Tomas-Sabado, 2009; Abdel-Khalek \& Tomas-Sabado, 2005; Ellis, Wahab, \& Ratnasingan, 2013), or non-religious groups (Morris \&McAdie, 2009). Other studies of Muslims have reported a positive correlation between afterlife beliefs and fear of death (Abdel-Khalek, 2002), positive correlations between intrinsic religiosity and death anxiety (Ghorbani et al., 2014), and positive correlations between Islamic spirituality and death anxiety (Ghorbani, Watson, Madani, \& Chen, 2016).

We assume that this level of death anxiety is a normal condition and natural consequence and is consistent with normative Islamic teachings. The Qur'an presents human life as a test and the afterlife as a test result (Shafer, 2012). Islam also depicts the trials of earthly life as a struggle with evil and the afterlife as a result of this confrontation (Ellens, 2012; Khan, Watson, Ali, \& Chen, 2018). From this perspective, death becomes the moment when the result of this struggle is made known. Naturally, this moment is seen with anxiety and tension among believers.

Although death anxiety has been widely discussed in the psychological literature, there is no evidence that death anxiety underlies any of the classes of psychiatric disorders (Flannelly, 2017a; $2017 b$ ). Studies suggest a positive effect of having a conscious awareness of death. Awareness of death can motivate people to enhance their physical health and prioritize growth-oriented goals, live up to positive standards and beliefs, build supportive relationships, encourage the development of peaceful, charitable communities, and foster open-minded and growth-oriented behaviors (for review see Vail et al., 2012).

The relationship between Islamic afterlife beliefs and death anxiety can also be understood from the perspective of meaning management theory (MMT) and the dual-system model of coping with death (Wong \& Tomer, 2011). MMT is based on existential positive psychology (Wong, 2005, 2009). According to MMT, human beings are meaning-seeking creatures with two central motivations: To survive and to find a meaning and reason for survival. A basic proposition of MMT is that the motivational tendencies of avoidance and approach may complement each other to maximize positive motivation. MMT predicts that the pursuit of meaning in life is the best way to increase death acceptance. MMT also assumes that better understanding of the goals of life can eliminate negative emotions related to death. MMT suggests that the best way to reduce death anxiety is to facilitate acceptance of death and to seek meaning in life. According to MMT, afterlife is more than symbolic immortality because it is typically associated with religious belief in a transcendental reality (Wong, Carreno, \& Gongora, 2018).

MMT emphasizes the adaptive benefits of death acceptance and meaning management. Harding, Flannelly, Weaver, and Costa (2005) reported that scales that measure belief in the afterlife were positively correlated with death acceptance. When threatened with death, individuals may depend on the cooperation and interaction between approach and avoidance systems. It is possible that Islamic afterlife beliefs, while triggering death anxiety, also 
stimulate acceptance of death and give meaning to life, which can have a positive psychological and social impact. Some Qur'anic verses stimulate this mechanism: "The ones whom the angels take in death, [being] good and pure; [the angels] will say, "Peace be upon you. Enter Paradise for what you used to do." (16:32). Surprisingly, the relationship between Islamic afterlife beliefs and death acceptance has not yet been examined. The current study predicts that Islamic afterlife beliefs are positively associated with both death acceptance and death anxiety.

\section{Heaven for Psychologists and Hell for Sociologists}

A review of the literature on the psychosocial impact of afterlife reward and punishment beliefs suggests a dilemma. While afterlife reward beliefs are positively associated with mental wellbeing indicators, they are negatively related to social wellbeing indicators. On the other hand, while afterlife punishment beliefs are negatively related to mental wellbeing indicators, they are positively related to social wellbeing indicators.

Belief in Heaven and a loving/benevolent God has been positively associated with self-esteem (Benson \& Spilka, 1973), self-worth (Francis, Gibson, \& Robbins, 2001), positive mood (Wiegand \& Weiss, 2006), life satisfaction (Steenwyk, Atkins, Bedics, \& Whitley Jr, 2010), higher levels of happiness, inversely related to depression (Wood et al., 2010), lower levels of anxiety and depression (Rosmarin, Pargament, \& Mahoney, 2009; Rosmarin, Pirutinsky, Pargament, \& Krumrei, 2009), and negatively associated with social anxiety, paranoia, obsession, and compulsion (Silton, Flannelly, Galek, \& Ellison, 2014). Belief in Heaven is associated with greater happiness and life satisfaction at both national and individual levels (Shariff \& Aknin, 2014).

In contrast, belief in Hell and a punitive God has been found to associate with psychological distress (Pargament, Koenig, \& Perez, 2000), low self-esteem (Benson \& Spilka, 1973; Francis et al., 2001; Phillips Iii, Pargament, Lynn, \& Crossley, 2004), depression and anxiety (Burker, Evon, Sedway, \& Egan, 2005; Exline, Park, Smyth, \& Carey, 2011; Fitchett et al., 2004; Jonker, Eurelings-Bontekoe, Zock, \& Jonker, 2008), paranoia, and obsession-compulsion (McConnell et al. 2006; Silton et al., 2014). Belief in Hell is associated with lower happiness and life satisfaction at the national and individual levels (Shariff \& Aknin, 2014).

Meanwhile, belief in the existence of Hell predicts rejection of moral relativism, and priming for moral objectivism endorses God's punishing characteristics (Sarkissian \& Phelan, 2019). In a large cross-national study of 143,197 participants from 67 countries, researchers found that crime rates are higher in nations where many people believe in Heaven but relatively fewer believe in Hell (Shariff \& Rhemtulla, 2012). In a small study of American college students, belief in a punitive God was found to be associated with lower levels of cheating; those who believed more in a loving God cheated more (Shariff \& Norenzayan, 2011). In developing countries, belief in Hell is associated with greater social stability and economic success (Barro \& McCleary, 2003), and increased intention to prosocial action (Yilmaz \& Bahekapili, 2016). Furthermore, studies indicate that believing that God's knowledge is infinite and that he punishes for moral transgressions increases prosocial behavior with strangers who adopt the same religion as theirs (Purzycki et al., 2016). In another study, belief in supernatural punishment was tied to prosocial behavior, and decreased antisocial behavior (Johnson, 2005).

We suggest that one of the reasons these contradictions appear is because contemporary psychology does not use an appropriate perspective to investigate the effects of religious beliefs of the afterlife. Contemporary psychology defines wellbeing from a hedonic perspective. For 
hedonic psychologists, wellbeing is the experience of pleasure and the achievement of a subjective sense of wellbeing (Kahneman, Diener, \& Schwarz, 1999). In the hedonic view, feeling good is the most important criterion for mental health. Whereas with afterlife beliefs, especially the Islamic beliefs of eschatological punishment, there is a greater focus on healthy functioning not just feeling good.

The eudaimonistic tradition may therefore provide a better perspective for understanding the psychosocial impact of afterlife reward and punishment beliefs. The eudaimonic conceptualization of wellbeing is premised on virtues, skills, and positive functioning (Keyes \& Annas, 2009(. In the eudaimonistic tradition, social wellbeing is an important factor for happiness; social wellbeing is how well an individual functions in their social life as a member of a larger society. Eudaimonia is a life of activity in accordance with virtue (Annas, 2000). Islam emphasizes virtues and righteousness rather than hedonism in conceptualizing mental wellbeing. Acting in accordance with these virtues is believed to lead to great attainment in the afterlife (Qur'an, 9: 89).

From the perspective of Muslims, it is difficult to separate belief in Heaven from belief in Hell. First, data for belief in Heaven and Hell from the 1981-1984, 1990-1993, 1994-1999, 1999-2004, and 2005-2007 waves of the World Values Surveys (WVS) for predominantly Muslim countries in Asia show uniformly high levels of belief in both Heaven and Hell (93\% and 91\%, respectively; Shariff \& Rhemtulla, 2012). This may mean that the two beliefs have a strong positive correlation and have the same psychosocial impact in the Muslim community. Second, in the Qur'an it is difficult to separate out the characteristics of God that represent mercy and punishment. Throughout the Qur'an, the reader is reminded how closely the two concepts are interrelated, for example, "[O Muhammad], inform My servants that it is I who am the Forgiving, the Merciful. And that it is My punishment which is the painful punishment” (Qur'an, 107:49-50). The Qur'an warns its followers of transgressing God's commands and only depending on His mercy (Qur'an, 7:169). The importance that orthodox Islamic theology attaches to balance in afterlife hope and fear is presented in one of the most widely accepted texts of creedal faith among Sunni Muslims. Imam Abu Ja'far al-Tahawi's text has long been the most widely acclaimed and indispensable reference works on Muslim beliefs. Tahawi explains one of the rules of Islamic faith, writing, "Anyone who feels secure (from Allah's punishment) or who loses hope (in His mercy) falls outside the realm of Islam. The correct course for the abl al-qiblab (or Muslims) lies in between these two ways" (Al-Ansari, 2000, p. 280).

As Islam projects a vision of life as a test and the afterlife as the result of that test, the Muslim may feel sadness, anxiety, and even depression due to his or her fear of not passing the test. Indeed, recent studies have indicated anxiety in Muslim attachments to God (Ghorbani et al., 2016). Islam encourages its followers to give priority to the happiness of others and society (Qur'an, 107: 1-7, 83: 1-4), and promises happiness in the afterlife in return for prosocial behaviors (Qur'an, 59: 9). One can therefore expect to find positive associations between Islamic afterlife beliefs and psychological variables related to pro-sociality.

\section{IARPB and Integrity}

Like most major world religions, Islam promotes prosocial behaviors and condemns antisocial behaviors. The Qur'an often links obedience to God's injunctions with the reward of Heaven and the violation of God's orders with punishment in Hell (4: 13-14). It is therefore logical to expect a positive relationship between reward and punishment beliefs in the afterlife and positive social behavior, as well as a negative relationship between reward and punishment beliefs 
in the afterlife and antisocial behavior. This may be the most important function of reward and punishment beliefs in the afterlife.

To test this hypothesis, this study examined the relationship of reward and punishment beliefs in the afterlife with integrity. "Integrity is defined as the strength of personal commitment to a principled ethical ideology; it determines the strength of the relationship between ethical beliefs and behavior" (Schlenker, 2008, p. 1117). In four studies, Schlenker (2008) presented evidence that integrity is negatively associated with a wide variety of antisocial behaviors and positively associated with prosocial behaviors. Integrity significantly and negatively predicted unethical and illegal activities, including lying, stealing, cheating, infidelity, broken promises, and drug use. Moreover, this effect was found even after statistically controlling for Machiavellianism, moral disengagement, and the tendency to justify morally questionable behavior. On the other hand, integrity positively predicted the reported frequencies of overall helping and volunteering even after statistically controlling for empathy and social desirability. Based on these findings, the present study hypothesized a positive relationship between IARPB and integrity.

\section{Study Aims and Hypotheses}

The dearth of valid instruments to measure afterlife beliefs of reward and punishment has been alluded to by many scholars (e.g., Abu-Raiya \& Hill, 2014; Alghorani, 2008; AlMarri, Oei, \& Al-Adawi, 2009; Amer, Hovey, Fox, \& Rezcallah, 2008; Joshanloo \& Rastegar, 2013; Khalaf et al., 2014; Khan \&Watson, 2006; Sahin \& Francis, 2002; Tiliouine, Cummins, \& Davern, 2009). The few measures that have included item content for afterlife beliefs have typically been single- or two-item measures (e.g., Jana-Masri \& Priester, 2007; Ji \& Ibrahim, 2007; Abu-Raiya, Pargament, Mahoney, \& Stein, 2008; Krauss et al.,2006) that measure general belief in the afterlife. Ghorbani and colleagues (2002, 2008) developed scales measuring religious commitment based on a desire to avoid Hell and to reach Heaven. However, the scales were tested with a relatively small sample of students from the Shi' ite minority (Ghorbani et al., 2002; Ghorbani et al., 2008). More recently, Ghayas and Batool (2017) developed their own measure of Islamic afterlife beliefs, however, the scale is in Urdu and has not been translated into English, and has only been tested with two Pakistani samples from the Punjab province. Moreover, Ghayas and Batool's study concentrated on the expectations and emotions of Muslims related to the afterlife and not on theological beliefs about the afterlife. Therefore, there is a need for valid and reliable measures of afterlife reward and punishment beliefs, especially for the broader Muslim world where religion plays a central role yet still suffers from a lack of empirical study (Abu-Raiya \& Hill, 2014; Raiya, Pargament, Stein, \& Mahoney, 2007).

The present study aimed to first develop a scale for Islamic afterlife reward and punishment beliefs (IARPB) based on normative Islamic theology. Second, the study set out to examine the relationship between IARPB, death anxiety, and death acceptance, as well as the relationship between IARPB and pro-sociality. For the purpose of analysis, we used a measure of integrity to represent pro-sociality. We proposed three hypotheses:

H1: Islamic afterlife reward and punishment beliefs positively associated with Muslim religiosity.

H2: Islamic afterlife reward and punishment beliefs positively associated with death anxiety, death acceptance, and integrity.

H3: Islamic afterlife reward and punishment beliefs explain the unique variance in death anxiety, death acceptance, and integrity beyond that accounted for by Muslim religiosity. 


\section{Methods}

\section{Participants and Procedures}

Participants were recruited from different faculties at five public and private Jordanian universities $(N=605)$. The sample was diverse in terms of college major: $18 \%$ Arts, $8 \%$ Applied Medical Sciences, 11\% Engineering, 9\% Veterinary, 9\% Agriculture, 11\% Sharia, 6\% Sciences, 7\% Economics, 10\% Information Technology, and 10\% Pharmacy. Participants were between 17 and 26 years old $(M=21.57, S D=1.77)$, and $48 \%$ were female. Questionnaires were administered in a classroom setting and the participants were provided with a brief oral and written explanation of the study aims and rationale. Informed consent was obtained from all participants.

\section{Measures}

Islamic afterlife reward and punishment belief (IARPB) scale. To develop the IARPB scale, an initial item pool was generated based on an extensive literature review and qualitative information obtained from Muslim secondary school students through interviews and qualitative exploratory research. Items then went through two stages of content validity enhancement via focus group interviews and evaluations by a panel of experts. Six lecturers of religious education from Jordanian universities (who were involved in generating the items) were invited to participate in a focus group interview, where the initial item pool was reviewed. An interview protocol was used to collect data on the clarity, relevancy, and understanding of items. The focus group participants then provided verbal and written feedback on how the items should be rephrased to avoid misunderstanding or confusion among the respondents. Items were then rewritten, difficult terminologies were replaced, and long items were shortened following the suggestions of the participants. Using back translation, the items for the IARPB scale were translated from Arabic to English, and were approved by two international specialists on Islamic afterlife beliefs. The first expert was Prof. J. Harold Ellens, editor of Heaven, Hell, and the Afterlife: Eternity in Judaism, Christianity, and Islam, and the second expert was Prof. Mohammad Hassan Khalil, editor of Between Heaven and Hell: Islam, Salvation, and the Fate of Others.

The IARPB scale consists of items that reflect the most important themes of afterlife reward and punishment as presented by the Qur'an (except item 5). The themes are: fate of believer, fate of unbeliever, eternity, and the mizan (the balance of deeds). Item 5 measures belief in purgatory, which is not explicitly referenced in the Qur'an, but is strongly supported by both Sunni and Shiite theology (Chittick, 2008). The IARPB were measured with a five-point Likert scale ( 1 = Strongly Disagree; $5=$ Strongly Agree). The score was computed as the mean of the items answered so that higher scores represented a greater degree of afterlife reward and punishment belief.

Muslim religiosity. Self-reports of religiosity were measured using a modified version of the Duke University Religion Index (Koenig \& Bussing, 2010). This is a five-item scale with three subscales: Organization Religious Activities (ORA), Non-Organization Activities (NORA), and Intrinsic Religiosity (IR). ORA were assessed by responses to "How often do you attend a mosque or religious meetings?", scored 1 (Never) to 6 (more than once a week). NORA were assessed by responses to "How often do you spend time with private religious activities such as prayer or Qur'an reading?" scored $1=$ rarely or never through $6=$ more than once a day. Three questions evaluated degrees of IR $(\alpha=.79)$ : "In my life I experience the presence of God"; "My religious beliefs are what is behind my whole approach to life"; and "I try hard to carry my religion over into all other dealings in life”. IR statements were scored 1= 'Strongly Disagree', to 
$5=$ 'Strongly Agree'. The score for IR was computed as the mean of the items answered; a high score indicated a higher level of religiosity.

Death anxiety. The single-item test of death anxiety, "I am afraid of death" was used to measure death anxiety. Previous studies have reported that single-item assessments are reliable across time and correlate moderately with multi-item instruments of death anxiety (AbdelKhalek, 1998).

Death acceptance. The short version of the Multidimensional Orientation toward Dying and Death Inventory (MODDI-F) was used to measure death acceptance (MacDougall \& Farreras, 2016). This version of the death acceptance scale comprises three items $(\alpha=.66)$ : "Somehow, the knowledge of my death is a part of my life that I view positively"; "I have a positive attitude to the process of dying as a necessary stage in my life"; "Basically, I am ready to accept that I have to die one day". Items were measured with a five-point Likert scale (1= Strongly Disagree through $5=$ Strongly Agree) with higher scores representing a greater degree of death acceptance.

Integrity. Integrity was measured with Schlenker's (2008) eighteen-item scale ( $\alpha=.70)$. Sample items include, "Regardless of concerns about principles, in today's world you have to be practical, adapt to opportunities, and do what is most advantageous for you." and "If done for the right reasons, even lying or cheating are ok." Items were measured with a five-point Likert scale (1 = Strongly Disagree through 5 = Strongly Agree). Negatively worded items were reverse-scored, with higher scores representing a greater degree of integrity. The scale has been shown to exhibit little social desirability bias (see Schlenker, 2008). The English versions of the instruments (Religiosity, Death Acceptance, and Integrity) were translated to Arabic using back-translation technique.

\section{Analytic Approach}

The data were managed and analyzed using SPSS 21.0 and Mplus 8.1. The data were first explored descriptively. Missing data levels were low, ranging from 3.5 to 5.5 percent, and were handled by multiple imputations method. In order to evaluate factor structure of the IARPB scale, data from the total sample were randomly split into two subsamples. The first subsample, composed of 302 participants (subsample 1), was used to conduct exploratory factor analysis (EFA) for the IARPB items. The second subsample, obtained from the remaining 303 participants (subsample 2), was used to perform confirmatory factor analysis (CFA) for the IARPB items using structural equation modelling (SEM).

The CFA was conducted using the robust maximum likelihood estimator to account for potential non-normal data. The following criteria were used to determine if the factor model displayed good fit to the data: Chi Square $\left(\chi^{2}\right) p>.05$, comparative fit index (CFI) and Tucker-Lewis Index (TLI) $\geq 0.95$, standardized root mean square residual (SRMR) $\leq 0.08$, and root mean square error of approximation (RMSEA) $\leq 0.06$ (Hu \& Bentler, 1999). Reliability estimations (Cronbach alpha and Greatest Lower Bound) were generated in $\mathrm{R}$ ver. 3.3.0 (The $\mathrm{R}$ Foundation for Statistical Computing, Vienna, Austria; https://www.r-project.org/) using the 'userfriendlyscience' package ver. 0.4-1 (http://userfriendlyscience.com).

\section{Results}

\section{Exploratory Factor Analysis for the IARPB Scale}

EFA was conducted using principal component analysis (PCA) method. Items correlated at least .11 with other items, suggesting reasonable factorability. The diagonals of the anti-image correlation matrix were over .5 , supporting the inclusion of each item in the factor analysis. The communalities were above .3 , except in Item $2(.246)$. Visual inspection of the scree plot indi- 
cated one factor. One component had an eigenvalue over the criterion of one (eigenvalue $=1.94$ ) and explained $38.9 \%$ of the variance. Each of the 5-items loaded high on a single component, ranging from 0.49 to 0.76 (Table 1). The Kaiser-Mayer-Olkin test verified the sampling adequacy for the analysis $(\mathrm{KMO}=0.69)$ and Bartlett's Test of sphericity indicated that the correlations between items were sufficiently large for PCA $\left(\chi^{2}(11)=142.99 ; p<.001\right)$.

\section{Confirmatory Factor Analysis for the LARPB Scale}

CFA was conducted on sample $2(\mathrm{~N}=303)$. Factorial validity was tested using robust maximum likelihood estimation. The model showed optimal fit to the data, $\chi^{2}=5.042(d f=5, p=0.410)$; $\mathrm{CFI}=1.00, \mathrm{TLI}=0.99, \mathrm{RMSEA}=0.005$ (90\% CI: 0.00-0.08), $\mathrm{SRMR}=0.027$. There were no modification indices needed to improve the model. The standardized regression coefficients were significant and ranged from 0.27 to 0.83 (Figure 1). Visual inspection and values of skewness and kurtosis indicated IARPB was left skewed (Table 2).

Table 1. Factor Loadings and Communalities for IARPB $(\mathrm{N}=302)$

\begin{tabular}{|l|c|c|}
\hline Items & $\begin{array}{l}\text { Factor } \\
\text { loading }\end{array}$ & Communalities \\
\hline $\begin{array}{l}\text { 1. I believe in Judgment Day, reward of Paradise, and punishment } \\
\text { in Hell }\end{array}$ & 0.64 & .41 \\
\hline 2. Infidels will never get out from Hell & 0.69 & .24 \\
\hline $\begin{array}{l}\text { 3. Dwellers of Paradise will live in its bliss forever } \\
\text { 4. The actions of the infidels will be set on the scale on the Day of } \\
\quad \text { Judgment }\end{array}$ & 0.79 & .58 \\
\hline $\begin{array}{l}\text { 5. Some of the Muslim sinners will be sent to Hell; then Allah } \\
\text { will take them out and send them to Paradise }\end{array}$ & 0.58 & .34 \\
\hline
\end{tabular}

The Factor explained $38.92 \%$ of the total variation of the items in the factor Eigenvalues = 1.94; $\mathrm{KMO}=0.69 ;$ Bartlett's test $=142.99 ; p<.001$.

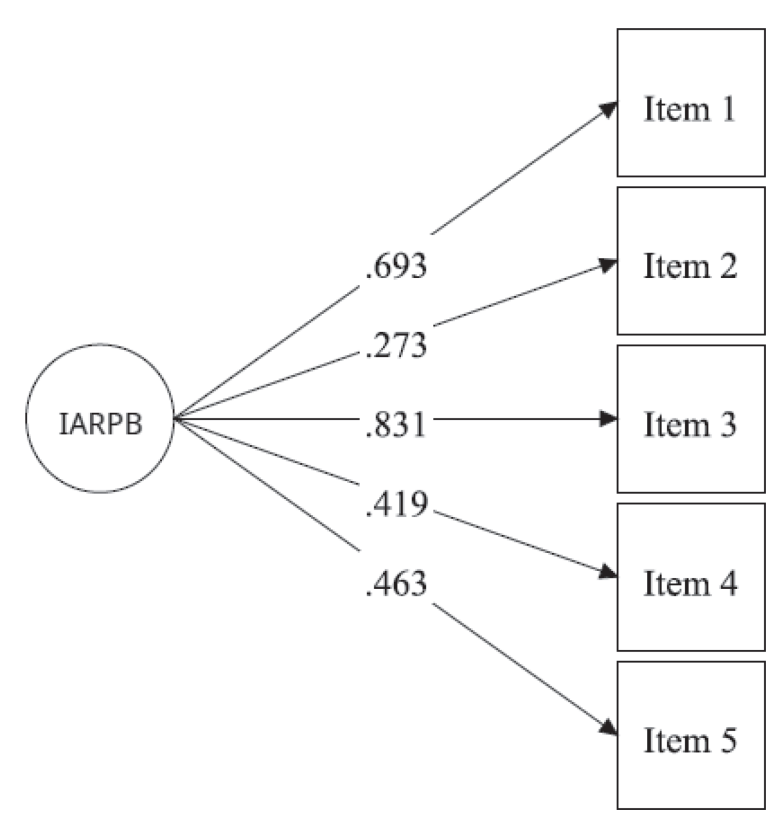

Figure 1. CFA Model Latent Factor Afterlife Reward and Punishment Beliefs Scale (IAPPB) - Jordanian Sample 
Table 2. Descriptive Statistics and Item-To-Total Correlations of IARPB Scale and Items $(N=605)$

\begin{tabular}{|l|c|c|c|c|c|}
\hline & M & SD & Skewness & Kurtosis & $\begin{array}{c}\text { Item-to-Total } \\
\text { Correlation }\end{array}$ \\
\hline IARPB & 4.15 & .59 & -1.21 & 2.45 & - \\
\hline Item 1 & 4.74 & .72 & -3.35 & 11.84 & .42 \\
\hline Item 2 & 3.48 & 1.14 & -.131 & -.74 & .24 \\
\hline Item 3 & 4.59 & .80 & -2.30 & 5.55 & .53 \\
\hline Item 4 & 4.06 & 1.06 & -1.10 & .71 & .33 \\
\hline Item 5 & 3.90 & .96 & -.76 & .46 & .36 \\
\hline
\end{tabular}

\section{Reliability of the IARPB Scale}

The Cronbach Alpha for IARPB was .60 [95\% CI:0.56, 0.65] above the minimal .60 as suggested by Hill (2013) for religion scales. However, Cronbach's alpha is not an ideal tool to measure reliability in realistic conditions ( $\mathrm{McNeish}$, 2017). Cronbach's alpha may underestimate the true reliability by as much as $20 \%$ when the tau equivalence assumption is violated- as is the case for IARPB and most psychological scales (Green \& Yang, 2009). Tau equivalence means that each item on a scale contributes equally to the total scale score. Furthermore, the degree of underestimation is greatest when scales have a fairly small number of items - IARPB is 5 items (Graham, 2006). In the presence of skewed items it is preferable to use the Greatest Lower Bound $g l b$ coefficient for testing reliability (Trizano-Hermosilla \& Alvarado, 2016). For IARPB the greatest lower bound $(g l b)=0.71$. According to Clark and Watson (Clark \& Watson, 1995), if one is measuring a broad higher order construct an average inter-item correlation should fall somewhere between .15 and .2 and individual inter-item correlations should fall some wherein the range of .15 to .50 . The average inter-item correlation for IARPB was .26 and individual inter-item correlations ranged between .24 to .53 (Table 2), indicting good consistency.

\section{Gender Differences}

The results indicated that there was no significant difference in IARPB between male and female participants, $t(603)=-1.06, p=.288$. The average IARPB score for men $(M=4.13$, $S D=0.64)$ did not differ significantly from that of women $(M=4.18, S D=0.53)$.

\section{Correlation Analysis}

As expected, the IARPB scale was modestly associated with Muslim Religiosity, IR, ORA, and NORA, $r s=.14$ to .44 (Table 3). Correlations between the IARPB scale and death anxiety, death acceptance, and integrity are provided in Table 3 . All correlations were significant and in the predicted direction.

\section{Multiple Regression Analysis}

Hierarchical regression was used to test the incremental validity of the IARPB scale. In step one, the Muslim Religiosity scales (IR, ORA, and NORA) were entered simultaneously. In step two, IARPB was entered to predict the unique variance of IARPB in death anxiety, death acceptance, and integrity. As Table 4 makes clear, significant $\Delta R^{2}$ and $\beta$ values were obtained for the IARPB in each analysis. IARPB explained the unique variance in death anxiety, death acceptance, and integrity beyond that accounted for by Muslim religiosity. 
Table 3. Means, Standard Deviation, and Pearson Correlation Matrix for Variables $(\mathrm{N}=605)$

\begin{tabular}{|l|c|c|c|c|c|c|c|c|c|}
\hline Scales & $\mathbf{M}$ & $\mathbf{S D}$ & $\mathbf{1}$ & $\mathbf{2}$ & $\mathbf{3}$ & $\mathbf{4}$ & $\mathbf{5}$ & $\mathbf{6}$ & $\mathbf{7}$ \\
\hline 1. IARPB & 4.1 & .59 & - & $.44^{* *}$ & $.14^{* *}$ & $.21^{* *}$ & $.21^{* *}$ & $.25^{* *}$ & $.21^{* *}$ \\
\hline 2. IR & 4.3 & .75 & & - & $.21^{* *}$ & $.38^{* *}$ & $.18^{* *}$ & $.32^{* *}$ & $.15^{* *}$ \\
\hline 3. ORA & 3.5 & 1.61 & & & - & $.33^{* *}$ & $-.10^{*}$ & $.10^{*}$ & -.02 \\
\hline 4. NORA & 3.7 & 1.71 & & & & - & .02 & $.23^{* *}$ & $.18^{* *}$ \\
\hline 5. DAn & 3.7 & 1.33 & & & & & - & -.06 & .00 \\
\hline 6. DAc & 3.9 & .79 & & & & & & - & $.24^{* *}$ \\
\hline 7. Integrity & 3.6 & .45 & & & & & & & - \\
\hline
\end{tabular}

Note. IARPB = Islamic Afterlife Reward and Punishment Beliefs; IR = Intrinsic Religiosity; ORA = Organizational religious activity; NORA $=$ Non-organizational religious activity; DAn $=$ Death anxiety; DAc $=$ Death acceptance.

${ }^{*}$ Correlation is significant at the 0.01 level (2-tailed)

${ }^{\star}$ Correlation is significant at the 0.05 level (2-tailed).

Table 4. Multiple Regression Analysis

\begin{tabular}{|l|c|c|c|c|c|c|}
\hline & \multicolumn{4}{|c|}{ First Step } & \multicolumn{2}{c|}{ Second Step } \\
\hline Scales & $\mathbf{R}^{2}$ & $\boldsymbol{\beta}$ for IR & $\boldsymbol{\beta}$ for ORA & $\begin{array}{c}\boldsymbol{\beta} \text { for } \\
\text { NORA }\end{array}$ & $\Delta \mathbf{R}^{2}$ & $\begin{array}{c}\boldsymbol{\beta} \text { for } \\
\text { IARPB }\end{array}$ \\
\hline DAn & $.05^{* * *}$ & $.22^{* * *}$ & $-.14^{* * *}$ & -.01 & $.02^{* * *}$ & $.17^{* * * *}$ \\
\hline DAc & $.11^{* * *}$ & $.27^{* * *}$ & .00 & $.12^{* *}$ & $.01^{* *}$ & $.13^{* *}$ \\
\hline Integrity & $.05^{* * *}$ & $.11^{*}$ & $-.11^{*}$ & $.18^{* * *}$ & $.02^{* * *}$ & $.17^{* * *}$ \\
\hline
\end{tabular}

Note. IARPB = Islamic Afterlife Reward and Punishment Beliefs; IR = Intrinsic Religiosity; ORA = Organizational religious activity; NORA $=$ Non-organizational religious activity; $\mathrm{DAn}=$ Death anxiety; DAc $=$ Death acceptance.

${ }^{*} p<.05 .{ }^{* *} p<.01^{* *} p<.001$.

\section{The Indirect Effect of LARPB on Death Anxiety and Death Acceptance}

The pattern of correlations refers to the possibility of two mechanisms through which IARPB affects death anxiety and death acceptance. It is possible that IARPB suppresses death anxiety by increasing organizational religious activity (Figure 2) and amplifies death acceptance by increasing non-organizational religious activity (Figure 3). The theoretical framework supports the possibility of these two mechanisms. IARPB encourages the increase of both organizational religious and non-organizational religious activity. The individual who sees life as a test and the afterlife as the results, his or her death anxiety will be reduced whenever he or she conducts religious activities. The practice of religious activities - especially the communal prayer five times a day - is a sign of his or her success in testing. On the other hand, non-organizational religious activity such as reading the Qur'an increases a person's harmony with the idea of life as a test, thus increasing death acceptance. This is supported by past studies indicating that death anxiety decreases as religiosity increases among Muslims (A1-Sabwah \& Abdel-Khalek, 2006).

To examine the existence of these two mechanisms, an ad hoc analysis was conducted to test for a negative indirect effect of IARPB on death anxiety through organizational religious 


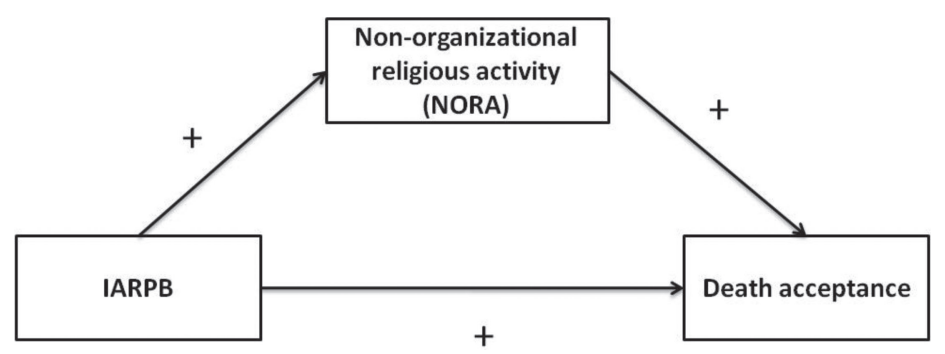

Figure 2. IARPB suppresses death anxiety by increasing ORA

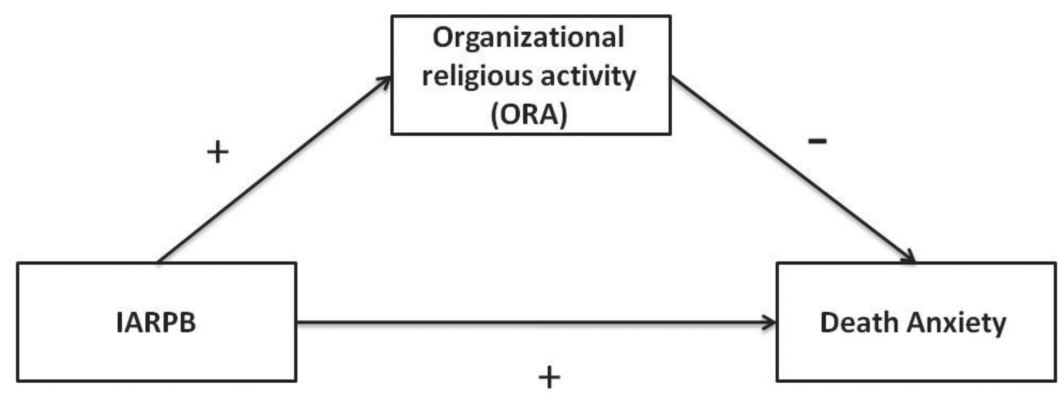

Figure 3. IARPB amplifies death acceptance by increasing NORA

activity and whether there was a positive indirect effect of IARPB on death acceptance through non-organizational religious activity. We used the bootstrapping procedure recommended by Preacher and Hayes (2008). They suggest using a bootstrapping procedure to compute a confidence interval (CI) around the indirect effect. A bootstrap 95\% bias-corrected confidence interval that does not include zero provides evidence of a significant indirect effect. The mediation analysis was performed by applying Hayes' PROCESS SPSS macro (model 4), using 5.000 bootstrapped samples to estimate the indirect effect (Hayes, 2013). The results indicate that IARPB has a significant positive effect on death anxiety $(b=0.5276, \mathrm{SE}=0.0891, t=5.9206$, $p=0.000)$, and a positive effect on organizational religious activity $(b=0.3795, \mathrm{SE}=0.1096, t=$ $3.4696, p=0.000)$. We also found a significant negative effect of organizational religious activity on death anxiety $(b=-0.1119, \mathrm{SE}=0.0328, t=-3.4111, p=0.000)$. As hypothesized, a significant negative indirect effect of IARPB on death anxiety via organizational religious activity was found (point estimate $=-0.0425,95 \% \mathrm{CI}=-0.0867$ to -0.0144 ).

Next, we tested the positive indirect effect of IARPB on death acceptance through nonorganizational religious activity. The results indicate that IARPB has a significant positive effect on death acceptance $(b=0.2864, \mathrm{SE}=0.0529, t=5.4100, p=0.000)$, and non-organizational religious activity $(b=0.6082, \mathrm{SE}=0.1148, t=5.2967, p=0.000)$. We also found a significant positive effect of non-organizational religious activity on death acceptance $(b=0.0865, \mathrm{SE}=$ $0.0184, t=4.7129, p=0.000$ ). As hypothesized, a significant positive indirect effect of IARPB on death acceptance via non-organizational religious activity was found (point estimate $=0.0526$, $95 \% \mathrm{CI}=0.0267$ to 0.0880 ). In sum, the results support the existence of the two mechanisms.

\section{Discussion}

The data supported the study hypotheses. The IARPB scale has good validity and reliability. The results further show that IARPB has incremental validity. As predicted, IARPB is positively related to both death anxiety and death acceptance as well as integrity. Results of the ad hoc 
analysis found a negative indirect effect of IARPB on death anxiety through organizational religious activity, and a positive indirect effect of IARPB on death acceptance through nonorganizational religious activity.

This is the first study that tests IARPB with an Arab sample, examining IARPB's relationship to both death acceptance and integrity. The results show some similarity with those of Ghorbani and colleagues (2014). IARPB, like the Afterlife Motivation scale, correlated positively with Muslim religiosity indexes, and there were no gender differences in the two scales. Both scales positively correlated with death anxiety. As we predicted, and in keeping with Ghorbani's study, intrinsic religiosity positively correlated with death anxiety. In addition, the current study found a positive correlation between IARPB and death acceptance. It is worth noting that we found no connection between death anxiety and death acceptance, unlike previous studies among Western samples that found a negative relationship (Harding, Flannelly, Weaver, \& Costa, 2005). It is possible to point out that the meaning management theory MMT and dual-system model of coping with death provides a better understanding of the feelings of Muslims toward death. Moreover, the positive relationship found between IARPB and integrity confirms previous studies showing that afterlife beliefs play a role in promoting positive social behavior (for a review see Saleam \& Moustafa, 2016).

However, this study is characterized by its exploratory nature and has several limitations resulting from the cross-sectional design of the research including the limited sample to university students and reliance on self-reports scales. The study also used only one item to measure death anxiety, which may have affected the reliability of the results. Therefore, generalizing the results of the study should be treated with caution. Nevertheless, the study indicates that beliefs in the afterlife may play an important role in the mental health of Muslim youth, which implies that these beliefs may play a greater role in later life stages, as other studies indicate that adults are usually more religious than young people (Pew, 2018).

The negative indirect effect of IARPB on death anxiety through organizational religious activity and the positive indirect effect of IARPB on death acceptance through non-organizational religious activity need more investigation. Future studies should examine these two mechanisms more closely to explore whether other variables moderate the relationship between IARPB and organizational and non-organizational religious activity. For example, faith-oriented reflection (Dover, Miner, \& Dowson, 2007) may moderate this relationship. Researchers should also consider how one believes in addition to what one believes. For example, results may differ depending on whether one believes in IARPB through reflection as opposed to social desirability or social confirmation. As we have already pointed out, the idea of life as a test and a struggle against vice and sin is central to the Islamic religion (Ellens, 2012; Shafer, 2012). Future studies might consider adding additional items to the IARPB scale that reflect this theological stance.

In conclusion, we propose that future studies about Islamic Afterlife beliefs take into account the differences between Western and Eastern cultures in the concept of wellbeing (Joshanloo, 2014). These differences are perhaps more evident in the study of afterlife beliefs than any other topic. Even the beliefs of Christianity about the afterlife are perhaps best understood from the perspective of Eastern cultures, given their Eastern origins. The concept of wellbeing in Western culture is related to self-enhancement, hedonism, mastery, satisfaction, avoiding suffering and often unrelated to spirituality and religion. In Eastern cultures, however, wellbeing is often closely tied to self-transcendence, eudaimonism, harmony, contentment, valuing suffering and relevance to spirituality and religion (Joshanloo, 2014).

Author Note: This research was supported by the University Putra Malaysia Putra grant scheme (Vote number 9518600). 


\section{References}

Abdel-Khalek, A. M. (1998). Single-versus multi-item scales in measuring death anxiety. Death Studies, $22(8), 763-772$.

Abdel-Khalek, A. M. (2002). Why do we fear death? The construction and validation of the reasons for death fear scale. Death Studies, 26(8), 669-680.

Abdel-Khalek, A. M., Lester, D., Maltby, J., \& Tomas-Sabado, J. (2009). The Arabic scale of death anxiety: Some results from east and west. OMEGA--Journal of Death and Dying, 59(1), 39-50.

Abdel-Khalek, A. M., \& Tomas-Sabado, J. (2005). Anxiety and death anxiety in Egyptian and Spanish nursing students. Death Studies, 29(2), 157-169.

Abu-Raiya, H. (2013). The psychology of Islam: current empirically based knowledge, potential challenges, and direction for future research. In K. I. Pargament, J. J. Exline \& J. W. Jones (Eds.), APA handbooks in psychology handbook of psychology, religion, and spirituality (Vol. 1) (pp. 681-695). Washington, DC: American Psychological Association.

Abu-Raiya, H., \& Hill, P. C. (2014). Appraising the state of measurement of Islamic religiousness. Psychology of Religion and Spirituality, 6(1), 22-32.

Abu-Raiya, H., Pargament, K. I., Mahoney, A., \& Stein, C. (2008). A psychological measure of Islamic religiousness: Development and evidence for reliability and validity. The International Journal for the Psychology of Religion, 18(4), 291-315.

Al-Ansari, M. A. H. (2000). Translation of the commentary on the creed of at-Tahawi by ibn Abi al-Izz. Riyad, S.A.: Ministry of Higher Education.

Al-Sabwah, M. N., \& Abdel-Khalek, A. M. (2006). Religiosity and death distress in Arabic college students. Death Studies, 30(4), 365-375.

Alghorani, M. A. (2008). Knowledge-practice measure of Islamic religiosity (KPMIR): A case of high school Muslim students in the United States. Journal of Muslim Mental Health, 3(1), 25-36.

AlMarri, T. S. K., Oei, T. P. S., \& Al-Adawi, S. (2009). The development of the short Muslim practice and belief scale. Mental Health, Religion and Culture, 12(5), 415-426.

Amer, M. M., Hovey, J. D., Fox, C. M., \& Rezcallah, A. (2008). Initial development of the brief Arab religious coping scale (BARCS). Journal of Muslim Mental Health, 3(1), 69-88.

Annas, J. (2000). Ancient philosophy: A very short introduction. Oxford: Oxford University Press.

Barro, R.J., \& McCleary, R. (2003). Religion and economic growth. American Sociological Review(68), 760-781.

Benson, P., \& Spilka, B. (1973). God image as a function of self-esteem and locus of control. Journal for the Scientific Study of Religion, 12(3), 297-310.

Burker, E. J., Evon, D. M., Sedway, J. A., \& Egan, T. (2005). Religious and non-religious coping in lung transplant candidates: Does adding God to the picture tell us more? Journal of Behavioral Medicine, 28(6), 513-526.

Chittick, W. C. (2008). Muslim eschatology. In J. L. Walls (Ed.), The Oxford handbook of eschatology (pp. 132-150). New York: Oxford University Press.

Clark, L. A., \& Watson, D. (1995). Constructing validity: Basic issues in objective scale development. Psychological Assessment, 7(3), 309-319.

Dastmalchian, A. (2017). Islam. In Y. Nagasawa \& B. Matheson (Eds.), The Palgrave handbook of the afterlife (pp. 153-173). London: Palgrave Macmillan. 
Dover, H., Miner, M., \& Dowson, M. (2007). The nature and structure of Muslim religious reflection. Journal of Muslim Mental Health, 2(2), 189-210.

Ellens, J. H. (2012). Ideas of apocalyptic eschatology in Islam. In J. H. Ellens (Ed.), Heaven, hell, and the afterlife: Eternity in Judaism, Christianity, and Islam (Vol. 3) (pp. 57-64). Westport, CT: Praeger.

Ellis, L., \& Wahab, E. A. (2013). Religiosity and fear of death: A theory-oriented review of the empirical literature. Review of Religious Research, 55(1), 149-189.

Ellis, L., Wahab, E. A., \& Ratnasingan, M. (2013). Religiosity and fear of death: A three nation comparison. Mental Health, Religion \& Culture, 16(2), 179-199.

Exline, J. J., Park, C. L., Smyth, J. M., \& Carey, M. P. (2011). Anger toward God: Social-cognitive predictors, prevalence, and links with adjustment to bereavement and cancer. Journal of Personality and Social Psychology, 100(1), 129-148.

Fitchett, G., Murphy, P. E., Kim, J., Gibbons, J. L., Cameron, J. R., \& Davis, J. A. (2004). Religious struggle: Prevalence, correlates and mental health risks in diabetic, congestive heart failure, and oncology patients. International Journal of Psychiatry in Medicine, 34(2), 179-196.

Flannelly, K. J. (2017a). Beliefs about life-after-death and psychiatric symptoms. In K. J. Flannelly (Ed.), Religious beliefs, evolutionary psychiatry, and mental health in America (pp. 173-182). Cham, Switzerland: Springer.

Flannelly, K. J. (2017b). Religion and death anxiety. In Religious beliefs, evolutionary psychiatry, and mental health in America (pp. 153-164). Cham, Switzerland: Springer.

Francis, L. J., Gibson, H. M., \& Robbins, M. (2001). God images and self-worth among adolescents in Scotland. Mental Health, Religion \& Culture, 4(2), 103-108.

Ghayas, S., \& Batool, S. S. (2017). Construction and validation of afterlife belief scale for Muslims. Journal of Religion and Health, 56(3), 861-875.

Ghorbani, N., Watson, P. J., Geranmayepour, S., \& Chen, Z. (2014). Muslim experiential religiousness: Relationships with attitude toward Islam, religious reflection, and basic needs satisfaction in Iranians. Research in the Social Scientific Study of Religion, 25, 53-72.

Ghorbani, N., Watson, P. J., Ghramaleki, A. F., Morris, R. J., \& Hood Jr, R. W. (2002). Muslim-Christian religious orientation scales: Distinctions, correlations, and cross-cultural analysis in Iran and the United States. The International Journal for the Psychology of Religion, 12(2), 69-91.

Ghorbani, N., Watson, P. J., Madani, M., \& Chen, Z. J. (2016). Muslim experiential religiousness: Spirituality relationships with psychological and religious adjustment in Iran. Journal of Spirituality in Mental Health, 18(4), 300-315.

Ghorbani, N., Watson, P. J., Omidbeiki, M., \& Chen, Z. J. (2016). Muslim attachments to God and the 'perfect man' (ensān-e kāmel): Relationships with religious orientation and psychological adjustment in Iran. Psychology of Religion and Spirituality, 8(4), 318-329.

Ghorbani, N., Watson, P. J., \& Shahmohamadi, K. (2008). Afterlife Motivation Scale: Correlations with maladjustment and incremental validity in Iranian Muslims. International Journal for the Psychology of Religion, 18(1), 22-35.

Graham, J. M. (2006). Congeneric and (essentially) tau-equivalent estimates of score reliability: What they are and how to use them. Educational and Psychological Measurement, 66(6), 930-944.

Green, S. B., \& Yang, Y. (2009). Commentary on coefficient alpha: A cautionary tale. Psychometrika, 74(1), 121-135.

Harding, S. R., Flannelly, K. J., Weaver, A. J., \& Costa, K. G. (2005). The influence of religion on death anxiety and death acceptance. Mental Health, Religion E Culture, 8(4), 253-261. 
Haque, A., Khan, F., Keshavarzi, H., \& Rothman, A. E. (2016). Integrating Islamic traditions in modern psychology: Research trends in last ten years. Journal of Muslim Mental Health, 10(1), 75-100.

Hayes, A. F. (2013). Introduction to mediation, moderation, and conditional process analysis: A regressionbased approach. New York: The Guilford Press.

Hill, P. C. (2013). Measurement assessment and issues in the psychology of religion and spirituality. In R. F. Paloutzian \& C. L. Park (Eds.), Handbook of the psychology of religion and spirituality (2nd ed.) (pp. 48-74). New York: Guilford Press.

Hu, L. T., \& Bentler, P. M. (1999). Cutoff criteria for fit indexes in covariance structure analysis: Conventional criteria versus new alternatives. Structural Equation Modeling, 6(1), 1-55.

Jana-Masri, A., \& Priester, P. E. (2007). The development and validation of a Qur'an-based instrument to assess Islamic religiosity: The religiosity of Islam scale. Journal of Muslim Mental Health, 2(2), 177-188.

Ji, C. H. C., \& Ibrahim, Y. (2007). Islamic doctrinal orthodoxy and religious orientations: Scale development and validation. International Journal for the Psychology of Religion, 17(3), 189-208.

Johnson, D. D. P. (2005). Gods punishment and public goods. Human Nature, 16(4), 410-446.

Johnson, K. A., \& Cohen, A. B. (2016). Authoritarian and benevolent god representations and the two sides of prosociality. Behavioral and Brain Sciences, 39, 1-65.

Jong, J., Ross, R., Philip, T., Chang, S.-H., Simons, N., \& Halberstadt, J. (2017). The religious correlates of death anxiety: A systematic review and meta-analysis. Religion, Brain E Behavior, 8(1), 4-20.

Jonker, H. S., Eurelings-Bontekoe, E. H. M., Zock, H., \& Jonker, E. (2008). Development and validation of the Dutch Questionnaire God Image: Effects of mental health and religious culture. Mental Health, Religion, and Culture, 11(5), 501-515.

Joshanloo, M. (2014). Eastern conceptualizations of happiness: Fundamental differences with western views. Journal of Happiness Studies, 15, 475-493.

Joshanloo, M., \& Rastegar, P. (2013). Development and initial validation of a scale to assess Sufi beliefs. Archive for the Psychology of Religion, 35(1), 49-69.

Kahneman, D., Diener, E., \& Schwarz, N. (Eds.). (1999). Wellbeing: Foundations of hedonic psychology. New York: Russell Sage Foundation.

Keyes, C. L. M., \& Annas, J. (2009). Feeling good and functioning well: Distinctive concepts in ancient philosophy and contemporary science. Journal of Positive Psychology, 4(3), 197-201.

Khalaf, D. R., Hlais, S. A. A., Haddad, R. S., Mansour, C. M., Pelissolo, A. J., \& Naja, W. J. (2014). Developing and testing an original Arabic religiosity scale. Middle East Current Psychiatry, 21(2), $127-138$.

Khan, Z. H., \& Watson, P. J. (2006). Construction of the Pakistani Religious Coping Practices Scale: Correlations with religious coping, religious orientation, and reactions to stress among Muslim university students. International Journal for the Psychology of Religion, 16(2), 101-112.

Khan, Z. H., Watson, P. J., Ali, H. N., \& Chen, Z. J. (2018). Greater jihad of society and self: Religious and psychological implications in Pakistani madrassa and university students. International Journal for the Psychology of Religion, 28(4), 271-280.

Koenig, H. G., \& Bussing, A. (2010). The Duke University Religion Index (DUREL): A five-item measure for use in epidemological studies. Religions, 1(1), 78-85.

Krauss, S. E., Hamzah, A. H., Suandi, T., Noah, S. M., Juhari, R., Manap, J.H., et al. (2006). Exploring regional differences in religiosity among Muslim youth in Malaysia. Review of Religious Research, 238-252. 
Lange, C. (2016). Paradise and hell in Islamic traditions. New York: Cambridge University Press.

Lange, C. R. (2008). Justice, punishment and the medieval Muslim imagination. New York: Cambridge University Press.

MacDougall, E. E., \& Farreras, I. G. (2016). The Multidimensional Orientation Toward Dying and Death Inventory (MODDI-F): Factorial validity and reliability in a US sample. Journal of Pain and Symptom Management, 51(6), 1062-1069.

McCleary, R. M. (2007). Salvation, damnation, and economic incentives. Journal of Contemporary Religion, 22(1), 49-74.

McNeish, D. (2018). Thanks coefficient alpha, we'll take it from here. Psychological Methods, 23(3), 412-433.

Morris, G. J., \& McAdie, T. (2009). Are personality, wellbeing, and death anxiety related to religious affiliation? Mental Health, Religion and Culture, 12(2), 115-120.

Murata, S., \& Chittick, W. C. (1994). The vision of Islam. New York: Paragon House.

Pargament, K. I., Koenig, H. G., \& Perez, L. M. (2000). The many methods of religious coping: Development and initial validation of the RCOPE. Journal of Clinical Psychology, 56(4), 519-543.

Pew Research Center. (2018, June). The age gap in religion around the world [Report]. Retrieved from: https:/www.pewforum.org/2018/06/13/the-age-gap-in-religion-around-the-world/

Phillips III, R. E., Pargament, K. I., Lynn, Q. K., \& Crossley, C. D. (2004). Self-directing religious coping: A deistic god, abandoning god, or no god at all?. Journal for the Scientific Study of Religion, 43(3), 409-418.

Preacher, K. J., \& Hayes, A. F. (2008). Asymptotic and resampling strategies for assessing and comparing indirect effects in multiple mediator models. Behavior Research Methods, 40(3), 879-891.

Purzycki, B. G., Apicella, C., Atkinson, Q. D., Cohen, E., McNamara, R. A., Willard, A. K., ... \& Henrich, J. (2016). Moralistic gods, supernatural punishment and the expansion of human sociality. Nature, 530(7590), 327-330.

Raiya, H. A., Pargament, K. I., Stein, C., \& Mahoney, A. (2007). Lessons learned and challenges faced in developing the Psychological Measure of Islamic Religiousness. Journal of Muslim Mental Health, 2(2), 133-154.

Rosmarin, D. H., Pargament, K. I., \& Mahoney, A. (2009). The role of religiousness in anxiety, depression, and happiness in a Jewish community sample: A preliminary investigation. Mental Health, Religion and Culture, 12(2), 97-113.

Rosmarin, D. H., Pirutinsky, S., Pargament, K. I., \& Krumrei, E. J. (2009). Are religious beliefs relevant to mental health among Jews? Psychology of Religion and Spirituality, 1(3), 180-190.

Sahin, A., \& Francis, L. J. (2002). Assessing attitude toward Islam among Muslim adolescents: The psychometric properties of the Sahin-Francis scale. Muslim Education Quarterly, 19(4), 35-47.

Saleam, J., \& Moustafa, A. A. (2016). The influence of divine rewards and punishments on religious prosociality. Frontiers in Psychology, 7(1149), 1-8. Retrieved from: https://www.frontiersin.org/ articles/10.3389/fpsyg.2016.01149/full

Sarkissian, H., \& Phelan, M. (2019). Moral objectivism and a punishing God. Journal of Experimental Social Psychology, 80,1-7.

Schlenker, B. R. (2008). Integrity and character: Implications of principled and expedient ethical ideologies. Journal of Social and Clinical Psychology, 27, 1078-1125.

Schlenker, B. R., Weigold, M. F., \& Schlenker, K. A. (2008). What makes a hero? The impact of integrity on admiration and interpersonal judgment. Journal of Personality, 76(2), 323-355. 
Shafer, G. (2012). A1-Ghayb wa al-`Akhirah: Heaven, Hell, and Eternity in the Qur`an. In J. H. Ellens (Ed.), Heaven, hell, and the afterlife: Eternity in Judaism, Christianity, and Islam (Vol. 3) (pp. 9-42). Westport, CT: Praeger.

Shariff, A. F., \& Aknin, L. B. (2014). The emotional toll of Hell: Cross-national and experimental evidence for the negative wellbeing effects of Hell beliefs. PloS One, 9(1), e85251. Retrieved from: https://journals.plos.org/plosone/article?id=10.1371/journal.pone.0085251

Shariff, A. F., \& Norenzayan, A. (2011). Mean gods make good people: Different views of God predict cheating behavior. International Journal for the Psychology of Religion, 21(2), 85-96.

Shariff, A. F., \& Rhemtulla, M. (2012). Divergent effects of beliefs in Heaven and Hell on national crime rates. PloS One, 7(6), e39048. Retrieved from: https://doi.org/10.1371/journal.pone.0039048

Silton, N. R., Flannelly, K. J., Galek, K., \& Ellison, C. G. (2014). Beliefs about God and mental health among American adults. Journal of Religion and Health, 53(5), 1285-1296.

Smith, J. I., \& Haddad, Y. Y. (2002). The Islamic understanding of death and resurrection. Albany, NY: State University of New York Press.

Steenwyk, S. A. M., Atkins, D. C., Bedics, J. D., \& Whitley Jr, B. E. (2010). Images of God as they relate to life satisfaction and hopelessness. International Journal for the Psychology of Religion, 20(2), 85-96.

Stuart, J. (2014). A qualitative analysis of Muslim young adults' adaptation experiences in New Zealand. Journal of Muslim Mental Health, 8(2), 21-46.

Tiliouine, H., Cummins, R. A., \& Davern, M. (2009). Islamic religiosity, subjective wellbeing, and health. Mental Health, Religion E Culture, 12(1), 55-74.

Trizano-Hermosilla, I., \& Alvarado, J. s. M. (2016). Best alternatives to Cronbach's alpha reliability in realistic conditions: congeneric and asymmetrical measurements. Frontiers in Psychology, 7(769), 1-10. Retrieved from: https://www.frontiersin.org/articles/10.3389/fpsyg.2016.00769/full

Vail, K. E., Juhl, J., Arndt, J., Vess, M., Routledge, C., \& Rutjens, B. T. (2012). When death is good for life considering the positive trajectories of terror management. Personality and Social Psychology Review, 16(4), 303-329.

Wiegand, K. E., \& Weiss, H. M. (2006). Affective reactions to the thought of "God": Moderating effects of image of God. Journal of Happiness Studies, 7(1), 23-40.

Wong, P. T. P. (2009). Existential positive psychology. In S. J. Lopez (Ed.), Encyclopedia of positive psychology (Vol. 1) (pp. 361-368). Oxford, UK: Wiley Blackwell.

Wong, P. T. P., Carreno, D. F., \& Gongora Oliver, B. (2018). Death acceptance and the meaning-centered approach to end-of-life care. In R. E. Menzies, R. G. Menzies, \& L. Iverach (Eds.), Curing the dread of death: Theory, research and practice (pp. 185-202). Samford Valley, Australia: Australian Academic Press.

Wong, P. T. P., \& Tomer, A. (2011). Beyond terror and denial: The positive psychology of death acceptance. Death Studies, 35(2), 99-106.

Wood, B. T., Worthington Jr, E. L., Exline, J. J., Yali, A. M., Aten, J. D., \& McMinn, M. R. (2010). Development, refinement, and psychometric properties of the Attitudes Toward God Scale (ATGS-9). Psychology of Religion and Spirituality, 2(3), 148-167.

Yilmaz, O., \& Bahekapili, H. G. (2016). Supernatural and secular monitors promote human cooperation only if they remind of punishment. Evolution and Human Behavior, 37(1), 79-84. 